\title{
ARTICLE Storage Stability of Vacuum-packaged Dry-aged Beef during Refrigeration at $4^{\circ} \mathrm{C}$
}

\section{† OPEN ACCESS}

\section{Received March 7, 2019 \\ Revised March 15, 2019 \\ Accepted March 15, 2019}

\footnotetext{
*Corresponding author: Cheorun Jo Department of Agricultural Biotechnology, Center for Food and Bioconvergence, and Research Institute of Agriculture and Life Science, Seoul National University, Seoul 08826, Korea

Tel: $+82-2-880-4820$

Fax: + 82-2-873-2271

E-mail: cheorun@snu.ac.kr

*ORCID

Seonjin Kim

https://orcid.org/0000-0001-7850-6632

Hyun Jung Lee

https://orcid.org/0000-0002-6891-8008

Minsu Kim

https://orcid.org/0000-0001-7038-1732

Ji Won Yoon

https://orcid.org/0000-0002-0233-7489

Dong Jin Shin

https://orcid.org/0000-0003-3315-667X

Cheorun Jo

https://orcid.org/0000-0003-2109-3798
}

\author{
Seonjin Kim ${ }^{1}$, Hyun Jung Lee ${ }^{1}$, Minsu Kim ${ }^{1}$, Ji Won Yoon ${ }^{1}$, Dong Jin Shin ${ }^{1}$, \\ and Cheorun Jo ${ }^{1,2, *}$ \\ ${ }^{1}$ Department of Agricultural Biotechnology, Center for Food and Bioconvergence, \\ and Research Institute of Agriculture and Life Science, Seoul National University, \\ Seoul 08826, Korea \\ ${ }^{2}$ Institute of Green Bio Science and Technology, Seoul National University, \\ Pyeongchang 25354, Korea
}

\begin{abstract}
Although the production of dry-aged beef has been increasing, most purveyors are unaware of the changes in quality that ensue after completion of the aging period and do not adhere to specific guidelines for its packaging and storage. The objective of this study was to investigate the storage stability of vacuum-packaged dry-aged beef based on changes in microbial, physicochemical, and sensory properties during refrigeration at $4{ }^{\circ} \mathrm{C}$ for $21 \mathrm{~d}$. The total aerobic bacterial count exceeded $6 \mathrm{Log} \mathrm{CFU} / \mathrm{g}$ at approximately day 11 and significantly increased after day 14 . Freshness indicators such as $\mathrm{pH}$ and volatile basic nitrogen content were acceptable until day 14 and 21, respectively. Based on the evaluation of overall sensory acceptability, the dry-aged beef was acceptable until $14 \mathrm{~d}$ without any sensory deterioration. Therefore, vacuum-packaged dry-aged beef could be stored for $11 \mathrm{~d}$ at $4^{\circ} \mathrm{C}$ without any adverse effect on its microbial and sensory quality.
\end{abstract}

Keywords microbiological quality, sensory quality, dry-aged beef, vacuum packaging, storage stability

\section{Introduction}

Dry aging is an aging technique used to enhance the tenderness and flavor of meat (Kim et al., 2018). It exposes the primal/sub-primal cuts and/or whole carcasses of beef without packaging under controlled temperature, relative humidity $(\mathrm{RH})$, and air flow conditions (Lee et al., 2017). For last decades, the application of dry aging had been limited due to its negative effects on salable yield followed by relatively high price (Lee et al., 2019a). Therefore, it had been in a small niche market and offered mostly in fine restaurants. However, in recent years, the consumption of dry-aged beef has been increasing worldwide, mainly due to the increase in consumer preference for its unique flavor (beefy and brown roasted) (Khan et al., 2016).

However, the direct exposure of meat during the dry aging process raises consumer

(C) Korean Society for Food Science of Animal Resources. This is an open access article distributed under the terms of the Creative Commons Attribution Non-Commercial License (http://creativecommons.org/licences/by-nc/3.0) which permits unrestricted non-commercial use, distribution, and reproduction in any medium, provided the original work is properly cited. 
concern over potential microbial contamination in dry-aged beef more than in wet-aged meat (Lee et al., 2017). According to previous studies, total aerobic bacterial count (TAB) was significantly higher in dry-aged beef when compared to that in wetaged beef after $19 \mathrm{~d}$ of aging (Li et al., 2014). Degeer et al. (2009) also reported the increase in TAB of dry-aged beef from 6.6 to $9.4 \mathrm{Log} \mathrm{CFU} / \mathrm{g}$ after $28 \mathrm{~d}$ of dry aging $(\mathrm{p}<0.05)$. Furthermore, significant growth of mold and yeast has been reported in dry-aged beef (Lee et al., 2018; Ryu et al., 2018). Changes in microbial growth are critical during the dry-aging process in that they can affect the initial numbers of microorganisms at the beginning of storage. Such changes may increase the risk of microbial contamination and meat spoilage, resulting in the deterioration of quality in dry-aged beef (Dashdorj et al., 2016). Therefore, the importance of microbial control during the storage of dry-aged beef has been reported by many researchers (Campbell et al., 2011; Choe et al., 2018; Dashdorj et al., 2016). The microbial quality of the outer surface of dry-aged beef is not directly incorporated into the expectation of quality or shelf-life of the products because the edible part of dry-aged beef is usually prepared after excising and trimming the crust completely. Therefore, the edible portion of internal dry-aged beef is less affected by outer surface microorganisms, contrary to consumer concerns. Instead it has been reported that mold and yeast produced in dry-aged beef were more impactful on flavor production of meat (Lee et al., 2019b). However, control of dry-aged beef remains important in the meat industry because microbial growth was higher in dry-aged beef than in wet/vacuum-aged beef.

Microbial control during storage can be attributed mainly to the packaging system (e.g., vacuum, wrap, and modified atmospheric packaging) (Lambert et al., 1991). Among them, vacuum packaging is likely the most effective in inhibiting microorganisms during storage as it eliminates air, which is an important factor in microbial growth. In addition, this system can retard lipid oxidation in meat during the storage period due to oxygen depletion (Mielnik et al., 2006). In consequence, vacuum packaging is widely used for improving the shelf-life of meat and meat products. Recently, consumption of dry-aged beef has been increasing worldwide due to its unique flavor. Despite this increase in consumption, information regarding the shelf-life of dry-aged beef is limited and guidelines and regulations are lacking. Therefore, the objectives of this study were to investigate the changes in microbial growth and physicochemical and sensory properties of vacuum-packaged dry-aged beef and to assess its storage stability at $4^{\circ} \mathrm{C}$.

\section{Materials and Methods}

\section{Dry-aging process and packaging conditions}

A total of nine strip sirloins were taken from nine beef carcasses (Holstein, quality grade 3; Jo et al., 2012) on three different slaughter days (three sirloins/trial) and dry aged in a dry aging cooler for $28 \mathrm{~d}$ (temperature, $4^{\circ} \mathrm{C}$; $\mathrm{RH}$, approximately $75 \%$; air flow, $2.5 \mathrm{~m} / \mathrm{s}$ ). After the completion of dry aging, the crusts were trimmed off of the samples and the sirloins were cut $\left(12.7 \times 7.6 \times 2.54 \mathrm{~cm}^{3}\right.$, length $\times$ width $\times$ height $)$ for packaging. Then the samples were vacuum packaged in polyethylene bags $\left(\mathrm{O}_{2}\right.$ permeability, $2.3 \mathrm{~mL} / \mathrm{m}^{2} / \mathrm{d}$ at $\left.38^{\circ} \mathrm{C}\right)$ and stored at refrigeration temperature $\left(4^{\circ} \mathrm{C}\right)$ for $21 \mathrm{~d}$. During the $21 \mathrm{~d}$ of storage, vacuum-packaged dry-aged beef was obtained at $0,7,14$, and $21 \mathrm{~d}$ for further analysis.

\section{Microbial growth}

Five grams of dry-aged beef was blended with $45 \mathrm{~mL}$ of $0.85 \%$ saline solution for 2 min using a laboratory stomacher (BagMixer $^{\circledR} 400$, Interscience Ind., St. Nom, France). One-hundred microliters from each sample dilution was spread on the surface of agar plates. TAB, mold/yeast, and lactic acid bacteria (LAB) were enumerated using plate count agar (Difco 
Laboratories, Detroit, MI, USA), yeast mold agar (Difco Laboratories), and de Man Rogosa and Sharpe agar (MRS, Difco Laboratories), respectively. After spreading the dilution on the agar, the agar plates for TAB and $\mathrm{LAB}$ were incubated at $37^{\circ} \mathrm{C}$ for $48 \mathrm{~h}$ and yeast mold agar plates were incubated at $25^{\circ} \mathrm{C}$ for $120 \mathrm{~h}$, respectively. The number of colonies was enumerated and expressed as Log CFU/g.

\section{Physicochemical properties}

\section{pH}

Each beef sample ( $1 \mathrm{~g}$ ) was homogenized with $9 \mathrm{~mL}$ of distilled deionized water (DDW) for $30 \mathrm{~s}$ (T10 basic, Ika Works, Staufen, Germany). The homogenates were centrifuged (Continent 512R, Hanil Co., Ltd., Incheon, Korea) at 2,265×g for 10 min. After centrifugation, each supernatant was filtered through filter paper (No. 4, Whatman PLC., Kent, UK) and each filtrate was measured using a $\mathrm{pH}$ meter (SevenGo, Mettler-Toledo International Inc., Schwerzenbach, Switzerland) after calibration with standard buffers.

\section{Volatile basic nitrogen (VBN)}

Three grams of each treatment sample was homogenized for $30 \mathrm{~s}$ (T25, Ika Works) followed by centrifugation (Continent 512R, Hanil Co., Ltd.) at 2,265 $\times$ g for $10 \mathrm{~min}$ and filtration through filter paper (Whatman No. 1, Whatman PLC). One hundred microliters of each sample with $0.01 \mathrm{~N}$ boric acid and indicator solution [0.66\% methyl red in ethanol:0.66\% bromocresol green in ethanol=1:1 (v/v)] was placed individually in the inner section of a conway (Sibata Ltd., Sitama, Japan); then, $1 \mathrm{~mL}$ of sample and $50 \%$ potassium carbonate was added into the outer section of the conway, after which the lid was sealed immediately. Then, the conway was incubated at $37^{\circ} \mathrm{C}$ for $1 \mathrm{~h}$ and titrated with $0.01 \mathrm{~N}$ hydrogen chloride. The VBN value was calculated as follows:

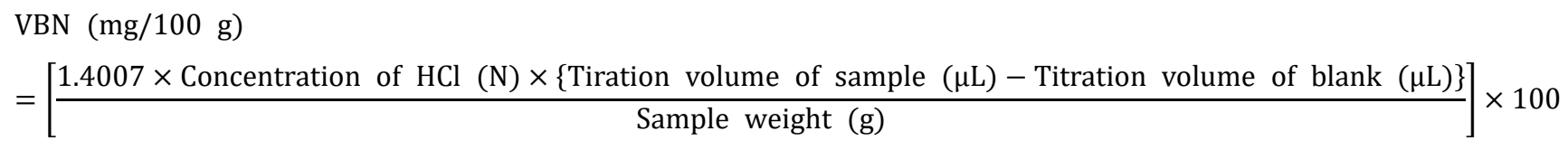

\section{2-Thiobarbituric acid reactive substances (TBARS) value}

Lipid oxidation was measured for the TBARS value using a spectrophotometer (X-ma 3100, Human Co. Ltd., Seoul, Korea). Five grams of each sample was homogenized with $15 \mathrm{~mL}$ of DDW and 7.2\% butylated hydroxyl toluene in ethanol for $30 \mathrm{~s}$ (T25, Ika Works). After homogenization, $2 \mathrm{~mL}$ of the homogenates was transferred to $15 \mathrm{~mL}$ Falcon ${ }^{\circledR}$ tubes and $4 \mathrm{~mL}$ of $20 \mathrm{mM}$ 2-thiobarbituric acid in $15 \%$ trichloroacetic acid was added. The tubes were heated in a laboratory water bath at $90^{\circ} \mathrm{C}$ for $30 \mathrm{~min}$, cooled, and centrifuged at 2,265×g for $15 \mathrm{~min}$ (HM-150IV, Hanil Co., Ltd.). The absorbance of the supernatant was measured at $532 \mathrm{~nm}$. The TBARS value was expressed as mg malondialdehyde (MDA)/kg of meat sample.

\section{Instrumental color}

After cutting and opening the package and allowing the beef to bloom for $30 \mathrm{~min}$, lightness, redness, and yellowness of the meat were measured and expressed as CIE L*, $a^{*}, b^{*}$ values, respectively, using a spectrophotometer (CM-5, Konica Minolta Censing Inc., Osaka, Japan). The colorimeter was calibrated using a standard white and black plate before each measurement. Color difference $(\Delta \mathrm{E})$ was calculated as follows: 


$$
\Delta \mathrm{E}=\left[\left(\mathrm{L}^{*}-\mathrm{L}^{*}{ }_{\mathrm{ref}}\right)^{2}+\left(\mathrm{a}^{*}-\mathrm{a}^{*}{ }_{\mathrm{ref}}\right)^{2}+\left(\mathrm{b}^{*}-\mathrm{b}^{*}{ }_{\mathrm{ref}}\right)^{2}\right]^{1 / 2}
$$

where $\mathrm{L}^{*}{ }_{\text {ref, }} \mathrm{a}{ }^{*}$ ref, and $\mathrm{b}{ }^{*}$ ref represents lightness, redness, and yellowness in vacuum-packaged dry-aged beef at day 0 , respectively.

\section{Myoglobin (Mb) content}

For $\mathrm{Mb}$ content and the composition of its related pigments, deoxymyoglobin (DeoxyMb), oxymyoglobin (OxyMb), and metmyoglobin (MetMb) were analyzed following the methods of Krzywicki (1979). Mb was extracted from $4 \mathrm{~g}$ beef samples with $20 \mathrm{~mL}$ of $0.4 \mathrm{M}$ phosphate buffer ( $\mathrm{pH}$ 6.8). Each sample was homogenized (T10 basic, Ika Works) for $30 \mathrm{~s}$ and the homogenates were stabilized for $1 \mathrm{~h}$ at refrigeration conditions $\left(4^{\circ} \mathrm{C}\right)$ with foil. After allowing to stand, the samples were centrifuged (Combi 514R, Hanil Co., Ltd.) at 5,000×g for $30 \mathrm{~min}$. The filtrates were filtered with filter paper (Whatman No. 1, Whatman PLC) and the absorbance of the supernatant was measured at 525, 572, and 700 nm using a spectrophotometer (X-ma 3100, Human Co. Ltd.).

\section{Texture profile analysis}

Texture profile (hardness, adhesiveness, springiness, chewiness, and cohesiveness) was analyzed with a texture analyzer (TA1, Lloyd Instruments Ltd., Fareham, UK). Ten grams of ground sample was placed into a petri dish $\left(35 \times 10 \mathrm{~mm}^{2}\right), \mathrm{cooked}$ in a laboratory water bath at $85^{\circ} \mathrm{C}$ for $15 \mathrm{~min}$, and cooled. The conditions of the texture analyzer were set as follows: pre-load speed $10 \mathrm{~mm} / \mathrm{min}$, post-load speed $2 \mathrm{~mm} / \mathrm{s}$, maximum cell load $50 \mathrm{~kg}$, compression level $60 \%$.

\section{Sensory evaluation}

Sensory evaluation was conducted with nine consumer panelists to determine the sensory properties of vacuum-packaged dry-aged beef during $21 \mathrm{~d}$ of storage (IRB no. 1810/003-001). There were three independent sensory tests for each storage day. The samples were cut into pieces of the same size $\left(4 \times 2 \times 2.54 \mathrm{~cm}^{3}\right)$ and grilled until the core temperature reached $72^{\circ} \mathrm{C}$. Sensory analysis was evaluated with a 9-point hedonic scale (1, extremely dislike; 9, extremely like) and scored for appearance, odor, taste, tenderness, juiciness, and overall acceptability of beef.

\section{Statistical analysis}

All experiments were conducted in triplicate and averaged $(n=3)$. Vacuum-packaged dry-aged beef samples at different storage days $(0,7,14$, and $21 \mathrm{~d})$ were analyzed in each trial. A generalized linear model was used to perform the analysis using SAS 9.4 (SAS Institute Inc., Cary, NC, USA) and results were reported as mean values with SEM. Significant differences among the mean values were determined on the basis of Tukey's multiple comparison test at a significance level of $\mathrm{p}<0.05$.

\section{Results and Discussion}

\section{Microbial growth}

Microbial growth of meat depends on all environmental conditions during the slaughter and aging process, ultimately impacting meat spoilage and quality deterioration (Nychas et al., 2008). Therefore, the control of microbial growth (especially 
$\mathrm{TAB}$ ) is important in meat during storage. In the Korean market, TAB count in meat and meat products is limited to $<6$ Log $\mathrm{CFU} / \mathrm{g}$ at the point of consumption (MFDS, 2018). In the present study, the initial numbers of TAB, LAB, mold, and yeast in vacuum-packaged dry-aged beef were 4.4, 2.4, 3.6, and 5.9 Log CFU/g, respectively (Fig. 1). During $21 \mathrm{~d}$ of storage, TAB count steadily increased and exceeded the legal standard at day 14 (6.5 Log CFU/g). Therefore, the shelf-life of vacuumpackaged dry-aged beef may be limited to less than $14 \mathrm{~d}$ of storage based on TAB count. Furthermore, the regression equation $\left(r^{2}=0.99\right)$ for vacuum-packaged dry-aged beef based on the quality limit of TBA revealed that the shelf-life for dryaged beef could possibly reach $11 \mathrm{~d}$ (data not shown) with vacuum packaging during refrigerated storage. Regarding important information for producers and sellers, vacuum-packaged dry-aged beef after completion of aging could be stored and sold within $11 \mathrm{~d}$.

LAB count in vacuum-packaged dry-aged beef also increased over the first $7 \mathrm{~d}$; these levels were maintained thereafter. However, given that the growth of LAB did not affect meat spoilage during storage in both vacuum- and wrap-packaged beef (Lee et al., 2018; Nychas et al., 2008), it was not considered a factor in the quality deterioration category. While mold count decreased significantly between days 14 and 21, possibly due to the depletion of oxygen - an element crucial for its growth (Kemp et al., 1983), yeast count fluctuated and reached its highest level at day 21 (Fig. 1). As the detection of mold and yeast is generally scarce in most meat and meat products, no recommendations for acceptable mold and yeast levels during storage are available. However, as the presence of mold and yeast has been consistently reported in dry-aged beef (Kim et al., 2018; Lee et al., 2018; Ryu et al., 2018), their impact on meat quality is currently being studied.

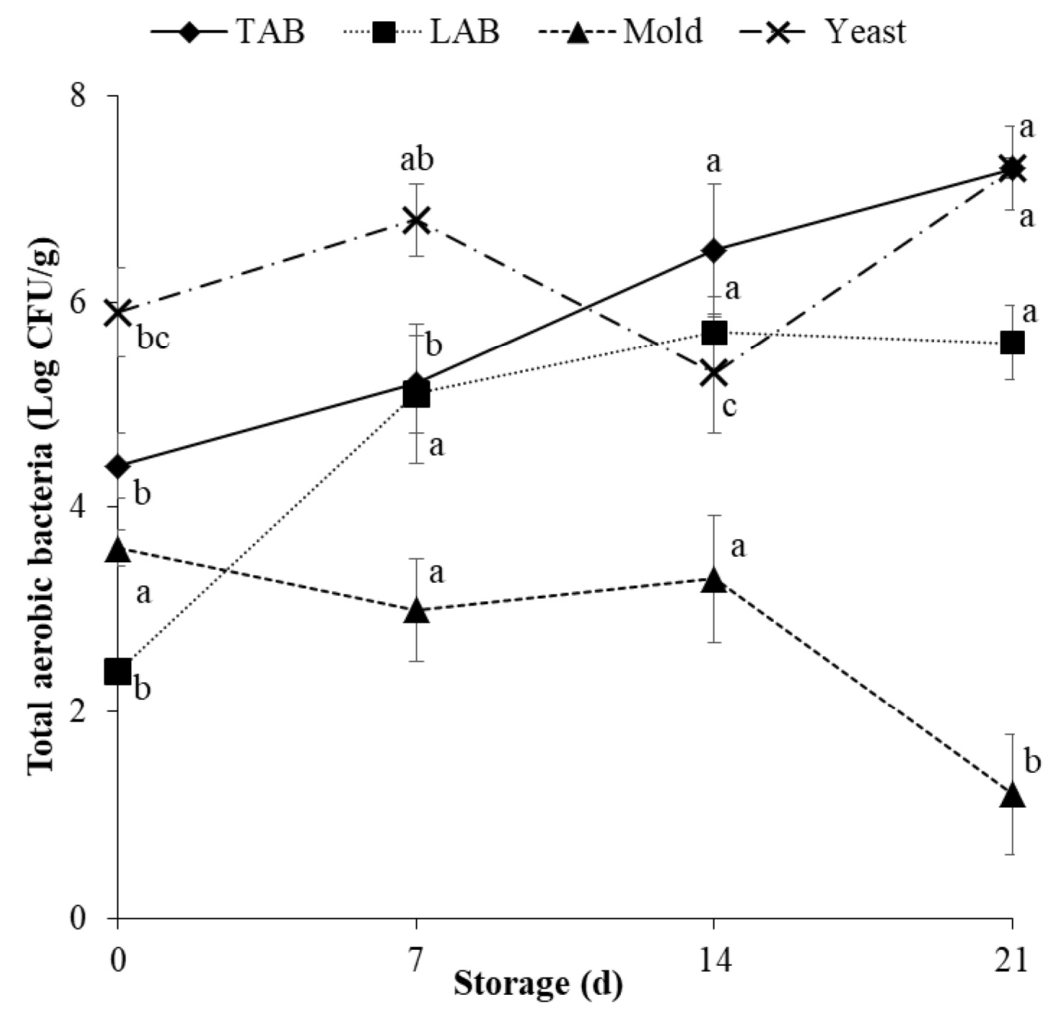

Fig. 1. Microbial growth (Log CFU/g) in vacuum-packaged dry-aged beef during $21 \mathrm{~d}$ of storage at refrigeration conditions $\left(4^{\circ} \mathrm{C}\right.$ ) (mean \pm SD). ${ }^{a-c}$ Different letters indicate a significant difference within the same microorganisms during $21 \mathrm{~d}$ of storage $(p<0.05)$. TAB, total aerobic bacteria; LAB, lactic acid bacteria. 


\section{Physicochemical properties}

\section{pH and VBN}

$\mathrm{pH}$ and VBN have been used to evaluate meat freshness/spoilage during storage because these indicators have been closely associated with microbial growth (Byun et al., 2003). During storage, the generation of protein-derived basic products (VBN including amine and/or ammonia) by the proteolysis of microorganisms can cause increases in $\mathrm{pH}$ as well as VBN content in meat (Byun et al., 2003; Lee et al., 2018). In contrast, decreases in $\mathrm{pH}$ can be caused mainly by the generation of lactic acid by LAB growth (Dave and Ghaly, 2011). According to Lee et al. (2018), the quality limits of pH and VBN in Korea are 6.2 and 20 $\mathrm{mg} / 100 \mathrm{~g}$, respectively, for fresh meat. In this study, the highest $\mathrm{pH}$ value was 5.69 occurring at day 14 and decreasing thereafter (Table 1). In contrast, the VBN content of vacuum-packaged dry-aged beef did not change significantly until $14 \mathrm{~d}$ of storage; however, thereafter, it increased and exceeded its recommended level for fresh meat $(20 \mathrm{mg} / 100 \mathrm{~g})$ at day 21. Consequently, the re-establishment of spoilage indicators for both dry- and wet-aged beef is necessary (Jang et al., 2014; Lee et al., 2018). Based on current recommendations, vacuum-packaged dry-aged beef may be considered fresh until day 14 at $4^{\circ} \mathrm{C}$.

\section{TBARS}

Lipid oxidation in meat is a very important factor, as it can cause quality deterioration (e.g., in color, flavor, texture, and nutritive value) in meat and meat products (Kim et al., 2018). It can be measured by the TBARS value and tends to increase during storage. However, in the present study, the TBARS value decreased significantly after $14 \mathrm{~d}$ of storage (Table 1), possibly as a result of excessive microbial growth in the vacuum-packaged dry-aged beef during that period (Fig. 1). According to Branen et al. (1978), the reaction of MDA and 2-thiobarbituric acid can be inhibited by protein-derived amines generated by microbial growth. Similarly, the TBARS value of raw pork decreased during storage (Kim et al., 2004). An et al. (2017) also reported a decrease in TBARS value in frozen pork over $7 \mathrm{~d}$ of storage with the degradation of MDA by microbial growth. Given that the initial TBARS value was high and did not increase significantly, it could not be considered to represent quality deterioration of vacuum-packaged dry-aged beef during storage. Therefore, the TBARS value is not a relevant metric impacting the shelf-life of vacuum-packaged dry-aged beef; this finding is consistent with Lee et al. (2018), who reported no correlation between the TBARS value and quality attributes of dry-aged beef. However, further investigation of $\mathrm{pH}, \mathrm{VBN}$, and lipid oxidation may be necessary to clarify their changes in dry-aged beef during storage.

Table 1. pH, volatile basic ntrogen, 2-thiobarbituric acid reactive substances, instrumental color (CIE $\mathrm{L}^{*}$, $\mathrm{a}^{*}$, and $\left.\mathrm{b}^{*}\right)$, and color difference of vacuum-packaged dry-aged beef during $21 \mathrm{~d}$ of storage at refrigeration conditions $\left(4^{\circ} \mathrm{C}\right)$

\begin{tabular}{|c|c|c|c|c|c|}
\hline \multirow{2}{*}{ Traits } & \multicolumn{4}{|c|}{ Storage (d) } & \multirow{2}{*}{ SEM $^{1)}$} \\
\hline & 0 & 7 & 14 & 21 & \\
\hline $\mathrm{pH}$ & $5.62^{\mathrm{c}}$ & $5.65^{\mathrm{b}}$ & $5.69^{\mathrm{a}}$ & $5.55^{\mathrm{d}}$ & 0.004 \\
\hline VBN (mg/100 g) & $16.92^{\mathrm{b}}$ & $17.15^{\mathrm{b}}$ & $19.03^{\mathrm{b}}$ & $23.92^{\mathrm{a}}$ & 0.678 \\
\hline TBARS (mg MDA/kg meat) & $0.98^{\mathrm{ab}}$ & $1.13^{\mathrm{a}}$ & $0.87^{\mathrm{b}}$ & $0.83^{\mathrm{b}}$ & 0.041 \\
\hline CIE L* & $33.42^{b}$ & $37.99^{\mathrm{a}}$ & $35.76^{\mathrm{ab}}$ & $35.59^{\mathrm{b}}$ & 0.524 \\
\hline CIE $a^{*}$ & $10.00^{\mathrm{c}}$ & $10.25^{\mathrm{c}}$ & $12.42^{\mathrm{a}}$ & $11.64^{\mathrm{b}}$ & 0.117 \\
\hline CIE b* & $6.35^{\mathrm{c}}$ & $6.35^{\mathrm{c}}$ & $9.50^{\mathrm{a}}$ & $7.83^{b}$ & 0.054 \\
\hline$\Delta \mathrm{E}$ & - & $6.11^{\mathrm{a}}$ & $5.53^{\mathrm{ab}}$ & $3.98^{\mathrm{b}}$ & 0.3664 \\
\hline
\end{tabular}

1) Standard error of the mean $(n=12)$.

${ }^{\mathrm{a}-\mathrm{d}}$ Different letters within the same row represent significant difference $(\mathrm{p}<0.05)$.

VBN, volatile basic nitrogen; TBARS, 2-thiobarbituric acid-reactive substance; MDA, malondialdehyde. 


\section{Instrumental color and Mb content}

Meat color can affect acceptability by consumers when they purchase meat and meat products at the market (Yong et al., 2018). CIE L*, $\mathrm{a}^{*}$, and $\mathrm{b}^{*}$ values are used to measure meat color; among them, CIE $\mathrm{a}^{*}$ may be important to consumers as it determines the redness of meat, which confers freshness at the market. Meat color is attributed to the chemical status of $\mathrm{Mb}$ (OxyMb, bright red color; MetMb, brown color; DeoxyMb, purple color) (Yong et al., 2018). Therefore, changes in Mb content is a main determinant for color stability during storage. Meat color and Mb content of vacuum-packaged dry-aged beef are shown in Tables 1 and 2, respectively. In the present study, significant increases in the composition of OxyMb was found between days 7 and 14, which was not expected, especially in the middle of vacuum packaging, as the generation of $\mathrm{OxyMb}$ is attributed exclusively to oxygen binding (Mancini and Hunt, 2005). However, Lee et al. (2018) also reported a sudden increase in OxyMb composition in wrap-packaged dry-aged beef at day 3. Hence, regardless of packaging methods, the composition of $\mathrm{OxyMb}$ may change during the storage of dry-aged beef based on unknown factors that require further investigation of the chemical changes of myoglobin in dry-aged beef. In contrast, OxyMb composition in vacuum-packaged dry-aged beef decreased $(\mathrm{p}<0.05)$ after day 14 of storage, possibly via its oxidation to MetMb with a decrease in $\mathrm{pH}$. Lower $\mathrm{pH}$ at day 21 may promote the oxidation of OxyMb to increase the content of MetMb (Faustman et al., 2010).

During the storage of vacuum-packaged dry-aged beef, CIE L* increased significantly at day 7 and decreased thereafter, whereas CIE $a^{*}$ and $b^{*}$ increased significantly between days 7 and 14 and then decreased (Table 1). The change in CIE L* may be related to microbial growth, especially TAB (Robach and Costilow, 1961). Meanwhile, the change in CIE a* could be affected by $\mathrm{OxyMb}$ content (Table 2), which reached its highest value at day 14 and exhibited a similar tendency with CIE $a^{*}$. Moreover, as CIE $b^{*}$ is positively correlated to CIE $a^{*}$, the tendency of CIE $b^{*}$ in vacuum-packaged dry-aged beef during storage was similar to that of $\mathrm{CIE} \mathrm{a}^{*}$. In addition, higher $\mathrm{pH}$ can contribute to the darker, redder, and more yellow color of meat by the increase in water holding capacity (Allen et al., 1997). In this study, the highest pH value of vacuum-packaged dry-aged beef at day 14 correlated with high CIE $\mathrm{a}^{*}$ and CIE $\mathrm{b}^{*}$ on day 14 of storage.

Total color difference $(\Delta \mathrm{E})$ of vacuum-packaged dry-aged beef did not change between day 7 and 14 but did change between day 7 and $21(p<0.05)$. However, as the CIE a* of vacuum-packaged dry-aged beef reached its highest at day 14 , the acceptability to the consumer may also be higher on this day when compared to the others.

Table 2. Myoglobin content and texture profile analysis of vacuum-packaged dry-aged beef during $21 \mathrm{~d}$ of storage at refrigeration conditions $\left(4^{\circ} \mathrm{C}\right)$

\begin{tabular}{|c|c|c|c|c|c|}
\hline \multirow{2}{*}{ Traits } & \multicolumn{4}{|c|}{ Storage (d) } & \multirow{2}{*}{$\mathrm{SEM}^{1)}$} \\
\hline & 0 & 7 & 14 & 21 & \\
\hline DeoxyMb (\%) & $3.38^{\mathrm{cz}}$ & $5.88^{\mathrm{bz}}$ & $9.37^{\text {ay }}$ & $5.77^{\mathrm{bz}}$ & 0.342 \\
\hline OxyMb (\%) & $57.91^{\text {bx }}$ & $52.27^{\mathrm{bx}}$ & $86.20^{\mathrm{ax}}$ & $37.68^{\text {cy }}$ & 1.531 \\
\hline MetMb (\%) & $38.71^{\text {by }}$ & $41.85^{\text {by }}$ & $4.43^{\mathrm{cz}}$ & $56.55^{\mathrm{ax}}$ & 1.675 \\
\hline Hardness $(\mathrm{N})$ & $389.91^{\mathrm{a}}$ & $310.65^{c}$ & $333.25^{\mathrm{b}}$ & $322.19^{\mathrm{bc}}$ & 4.022 \\
\hline Adhesiveness (kgf.mm) & -0.01 & -0.03 & 0.01 & 0.02 & 0.022 \\
\hline Springiness & $0.58^{\mathrm{ab}}$ & $0.61^{\mathrm{a}}$ & $0.55^{\mathrm{bc}}$ & $0.55^{\mathrm{c}}$ & 0.006 \\
\hline Chewiness $(\mathrm{N})$ & $147.98^{\mathrm{a}}$ & $104.69^{b}$ & $93.58^{\mathrm{b}}$ & $98.01^{\mathrm{b}}$ & 5.874 \\
\hline Cohesiveness & $0.82^{\mathrm{a}}$ & $0.56^{\mathrm{b}}$ & $0.50^{\mathrm{d}}$ & $0.52^{\mathrm{c}}$ & 0.004 \\
\hline
\end{tabular}

1) Standard error of the mean $(\mathrm{n}=12)$.

${ }^{a-d}$ Different letters within the same row represent significant difference $(\mathrm{p}<0.05)$.

${ }^{x-z}$ Different letters within the same column represent significant difference $(p<0.05)$.

$\mathrm{Mb}$, myoglobin; DeoxyMb, deoxymyoglobin; OxyMb, oxymyoglobin; MetMb, metmyoglobin. 
Table 3. Sensory properties of vacuum-packaged dry-aged beef during $21 \mathrm{~d}$ of storage at refrigeration conditions $\left(4^{\circ} \mathrm{C}\right)$

\begin{tabular}{|c|c|c|c|c|c|}
\hline \multirow{2}{*}{ Traits } & \multicolumn{4}{|c|}{ Storage (d) } & \multirow{2}{*}{ SEM $^{1}$} \\
\hline & 0 & 7 & 14 & 21 & \\
\hline Appearance & $6.30^{2)}$ & 6.04 & 6.07 & 5.63 & 0.223 \\
\hline Odor & 6.19 & 6.26 & 6.11 & 5.70 & 0.140 \\
\hline Taste & 6.59 & 6.04 & 6.00 & 5.63 & 0.220 \\
\hline Tenderness & 6.33 & 5.70 & 5.74 & 6.22 & 0.260 \\
\hline Juiciness & $6.33^{\mathrm{a}}$ & $5.85^{\mathrm{ab}}$ & $5.55^{\mathrm{b}}$ & $5.59^{\mathrm{ab}}$ & 0.169 \\
\hline Overall acceptability & $6.44^{\mathrm{a}}$ & $5.96^{\mathrm{ab}}$ & $5.78^{\mathrm{ab}}$ & $5.41^{b}$ & 0.183 \\
\hline
\end{tabular}

1) Standard error of the mean $(\mathrm{n}=12)$.

2) 1 , extremely dislike; 5 , neither dislike nor like; 9 , extremely like.

${ }^{\mathrm{a}, \mathrm{b}}$ Different letters within the same row represent significant difference $(\mathrm{p}<0.05)$.

\section{Texture profile analysis}

Texture profile analysis (i.e., hardness, springiness, chewiness, and cohesiveness) is useful to predict the sensory texture of cooked meat and adhesiveness can reveal texture defects like slime (Perez-Santaescolastica et al., 2018). In this study, the adhesiveness of vacuum-packaged dry-aged beef did not change significantly during $21 \mathrm{~d}$ of storage (Table 2), signifying that deterioration in texture was not observed in vacuum-packaged dry-aged beef during storage. In contrast, the values of other parameters decreased significantly at day seven, possibly due to protein degradation by microbial growth during storage (Fig. 1). Texture was maintained thereafter, except for hardness and springiness (first and second bites of hardness; De Huidobro et al., 2005) (Table 2). Hardness decreased at day $7(p<0.05)$, similar to the other parameters; however, it increased slightly but significantly at day 14 , whereas springiness decreased only at day $21(\mathrm{p}<0.05)$. Considering all of the results from texture profile analysis, we assumed that the texture of vacuum-packaged dry-aged beef may not be substantially different after $7 \mathrm{~d}$ of storage.

\section{Sensory evaluation}

In our previous study of wrap-packaged dry-aged beef, appearance and odor did not change $(\mathrm{p}<0.05)$, whereas taste and overall acceptability significantly decreased at day 7 (Lee et al., 2018). In the present study, sensory properties (appearance, odor, taste, tenderness, juiciness, and overall acceptability) of vacuum-packaged dry-aged beef were evaluated at 7-d interval over $21 \mathrm{~d}$ (Table 3). All parameters showed no significant changes throughout the entire storage period, except for juiciness and overall acceptability $(\mathrm{p}<0.05)$. Juiciness decreased significantly at day 14 , while overall acceptability did not change until $14 \mathrm{~d}$ of storage, significantly decreased thereafter.

Taken the results together from the present study, vacuum-packaged dry-aged beef could be stored for $11 \mathrm{~d}$ at $4^{\circ} \mathrm{C}$ without any adverse effect on its microbial and sensory quality.

\section{Conflict of interest}

The authors declare no potential conflict of interest.

\section{Acknowledgements}

This study was supported by "High Value-added Food Technology Development Program (Project No. 118042)," Korea 
Institute of Planning and Evaluation for Technology in Food, Agriculture, Forestry and Fisheries. Also, this work was supported by the BK21 Plus Program of the Department of Agricultural Biotechnology, Seoul National University, Seoul, Korea.

\section{Author Contributions}

Conceptualization: Lee HJ, Jo C. Investigation: Kim S, Kim M, Yoon JW, Shin DJ. Writing - original draft: Kim S, Lee HJ. Writing - review \& editing: Kim S, Lee HJ, Kim M, Yoon JW, Shin DJ, Jo C.

\section{Ethics Approval}

This research was approved by the Seoul National University Institutional Review Board (IRB\# 1810/003-001).

\section{References}

Allen CD, Russell SM, Fletcher DL. 1997. The relationship of broiler breast meat color and $\mathrm{pH}$ to shelf-life and odor development. Poult Sci 76:1042-1046.

An JY, Yong HI, Kim SY, Yoo HB, Kim YY, Jo C. 2017. Quality of frozen pork from pigs fed diets containing palm kernel meal as an alternative to corn meal. Korean J Food Sci Anim Resour 37:191-199.

Branen AL. 1978. Interaction of fat oxidation and microbial spoilage in muscle foods. Proceedings of Annual Reciprocal Meat Conference, University of Connecticut, Mansfield, CT, USA. pp 156-161.

Byun JS, Min JS, Kim IS, Kim JW, Chung MS, Lee M. 2003. Comparison of indicators of microbial quality of meat during aerobic cold storage. J Food Prot 66:1733-1737.

Campbell AW, Maclennan G, Judson HG, Lindsay S, Behrent MR, Mackie A, Kerslake JI. 2011. Brief communication: The effects of different forage types on lamb performance and meat quality. Proceedings of the New Zealand Society of Animal Production, Invercargill, New Zealand. pp 208-210.

Choe J, Kim KT, Lee HJ, Oh J, Kim HC, Park B, Choi YI, Jo C. 2018. Storage stability of dry-aged beef: The effects of the packaging method and storage temperature. Korean J Agric Sci 45:211-218.

Dashdorj D, Tripathi VK, Cho S, Kim Y, Hwang I. 2016. Dry aging of beef: Review. J Anim Sci Technol 58:20-30.

Dave D, Ghaly AE. 2011. Meat spoilage mechanisms and preservation techniques: A critical review. Am J Agric Biol Sci 6:486-510,

De Huidobro FR, Miguel E, Blazquez B, Onega E. 2005. A comparison between two methods (Warner-Bratzler and texture profile analysis) for testing either raw meat or cooked meat. Meat Sci 69:527-536.

DeGeer SL, Hunt MC, Bratcher CL, Crozier-Dodson BA, Johnson DE, Stika JF. 2009. Effects of dry aging of bone-in and boneless strip loins using two aging processes for two aging times. Meat Sci 83:768-774.

Faustman C, Sun Q, Mancini R, Suman SP. 2010. Myoglobin and lipid oxidation interactions: Mechanistic bases and control. Meat Sci 86:86-94.

Jang A. 2014. Study of meat freshness (spoilage) standard evaluation. Ministry of Food and Drug Safety, Korea.

Jo C, Cho SH, Chang J, Nam KC. 2012. Keys to production and processing of Hanwoo beef: A perspective of tradition and science. Animal Front 2:32-38. 
Kemp JD, Langlois BE, Fox JD. 1983. Effect of potassium sorbate and vacuum packaging on the quality and microflora of dry-cured intact and boneless hams. J Food Sci 48:1709-1714.

Khan MI, Jung S, Nam KC, Jo C. 2016. Postmortem aging of beef with a special reference to the dry aging. Korean J Food Sci Anim Resour 36:159-169.

Kim JK, Jo C, Kim HJ, Lee KH, Kim YJ, Byun MW. 2004. Relationship of specific microbial growth and TBARS value in radiation-sterilized raw ground pork. Prevent Nutr Food Sci 9:312-316.

Kim SY, Yong HI, Nam KC, Jung S, Yim DG, Jo C. 2018. Application of high temperature $\left(14^{\circ} \mathrm{C}\right)$ aging of beef $M$. semimembranosus with low-dose electron beam and X-ray irradiation. Meat Sci 136:85-92.

Krzywicki K. 1979. Assessment of relative content of myoglobin, oxymyoglobin and metmyoglobin at the surface of beef. Meat Sci 3:1-10.

Lambert AD, Smith JP, Dodds KL. 1991. Shelf life extension and microbiological safety of fresh meat-A review. Food Microbiol 8:267-297.

Lee HJ, Choe J, Kim KT, Oh J, Lee DG, Kwon KM, Choi YI, Jo C. 2017. Analysis of low-marbled Hanwoo cow meat aged with different dry-aging methods. Asian-Australas J Anim Sci 30:1733-1738.

Lee HJ, Choe J, Kim M, Kim HC, Yoon JW, Oh SW, Jo C. 2019a. Role of moisture evaporation in the taste attributes of dryand wet-aged beef determined by chemical and electronic tongue analyses. Meat Sci 151:82-88.

Lee HJ, Choe J, Yoon JW, Kim S, Oh H, Yoon Y, Jo C. 2018. Determination of salable shelf-life for wrap-packaged dry-aged beef during cold storage. Korean J Food Sci Anim Resour 38:251-258.

Lee HJ, Yoon JW, Kim M, Oh H, Yoon Y, Jo C. 2019b. Changes in microbial composition on the crust by different air flow velocities and their effect on sensory properties of dry-aged beef. Meat Sci 153:152-158.

Li X, Babol J, Bredie WL, Nielsen B, Tomankova J, Lundstrom K. 2014. A comparative study of beef quality after ageing longissimus muscle using a dry ageing bag, traditional dry ageing or vacuum package ageing. Meat Sci 97:433-442.

Mancini RA, Hunt MC. 2005. Current research in meat color. Meat Sci 71:100-121.

Mielnik MB, Olsen E, Vogt G, Adeline D, Skrede G. 2006. Grape seed extract as antioxidant in cooked, cold stored turkey meat. LWT-Food Sci Technol 39:191-198.

Ministry of Food and Drug Safety. The regulation of microbial level in meat and meat products in Korea. Available from: http://www.law.go.kr/admRulLsInfoP.do?chrClsCd=\&a

dmRulSeq=2100000109889. Accessed at Jan 3, 2018.

Nychas GJE, Skandamis PN, Tassou CC, Koutsoumanis KP. 2008. Meat spoilage during distribution. Meat Sci 78:77-89.

Perez-Santaescolastica C, Carballo J, Fulladosa E, Garcia-Perez JV, Benedito J, Lorenzo JM. 2018. Effect of proteolysis index level on instrumental adhesiveness, free amino acids content and volatile compounds profile of dry-cured ham. Food Res Int 107:559-566.

Robach DL, Costilow RN. 1961. Role of bacteria in the oxidation of myoglobin. Appl Microbiol 9:529-533.

Ryu S, Park MR, Maburutse BE, Lee WJ, Park DJ, Cho S, Hwang I, Oh S, Kim Y. 2018. Diversity and characteristics of the meat microbiological community on dry aged beef. J Microbiol Biotechnol 28:105-108.

Yong HI, Han M, Kim HJ, Suh JY, Jo C. 2018. Mechanism underlying green discolouration of myoglobin induced by atmospheric pressure plasma. Sci Rep 8:9790-9799. 